\author{
Н.В. Корочанская ${ }^{1,2, *}$, В.М. Дурлештер ${ }^{1,2}$, О.В. Ковалевская ${ }^{2}$, С.Н. Серикова ${ }^{1,2}$, \\ К.И. Попандопуло ${ }^{1}$ \\ 1 ФГБОУ ВО «Кубанский государственный медицинский университет» Министерства здравоохранения \\ Российской Федерачии, Краснодар, Российская Федерачия \\ 2 ГБУЗ Краевая клиническая больница № 2 Министерства здравоохранения Краснодарского края, Краснодар, \\ Россииская Федерачия
}

Цель исследования: проанализировать динамику заболеваемости и смертности от болезней органов пищеварения, а также качество оказания медицинской помощи гастроэнтерологическим пациентам в Краснодарском крае.

Материал и методы. Анализ проводился по данным формы C 51 «Распределение умерших по полу, возрастным группам и причинам смерти» Территориального органа Федеральной службы государственной статистики по Краснодарскому краю за период с 2006 по 2018 год, а также на основании изучения базы данных блока «Демография» системы управления здравоохранением Краснодарского края программного продукта «Парус» в течение 6 месяцев 2019 года. Рецензированию подверглись 1341 медицинская карта пациентов, получающих медицинскую помощь в амбулаторных условиях, и истории болезни лиц, умерших от болезней органов пищеварения в 2017-2019 годах.

Результаты. В структуре общей заболеваемости населения Краснодарского края болезни органов пищеварения занимают четвертое место (7,1 \%). За изучаемый период (13 лет) структура смертности населения края от БОП существенно не изменилась: на долю болезней печени приходится около 70 \% причин смерти от БОП лиц трудоспособного возраста, на втором месте - патология поджелудочной железы (13,5 \%), и практически равные доли имеют язвенная болезнь желудка, двенадцатиперстной кишки и «прочие болезни органов пищеварения» (8,8 и 7,7 \% соответственно). В этиологической структуре циррозов печени лидируют вирусные (39 \%) и алкогольные (36 \%) заболевания печени, причем частота вирусных поражений печени имеет тенденцию к снижению, а удельный вес циррозов печени в исходе неалкогольной жировой болезни печени (НАЖБП) прогрессивно увеличивается, достигнув в 2017-2018 годах 7 \%. В группе больных с воспалительными заболеваниями поджелудочной железы превалируют мужчины (66,9%), нередко злоупотребляющие алкогольными напитками. Третьей по значению причиной смертности от БОП в Краснодарском крае являются патологические состояния, возникшие в верхних отделах желудочно-кишечного тракта (острая язва желудка, двенадцатиперстной кишки с кровотечением, прободением), у лиц старших возрастных групп, принимающих дезагреганты и нестероидные противовоспалительные препараты (71,8 \%).

Выводы. Основными причинами смерти населения Краснодарского края от болезней органов пищеварения в молодом возрасте являются употребление алкоголя с вредными для здоровья последствиями, у лиц старших возрастных групп - отсутствие профилактики язвообразования и неадекватная эрадикация Неlicobacter pylori у лиц, принимающих нестероидные противовоспалительные препараты и дезагреганты.

Ключевые слова: заболеваемость, смертность, заболевания органов пищеварения

Конфликт интересов: авторы заявляют об отсутствии конфликта интересов.

Для цитирования: Корочанская Н.В, Дурлештер В.М., Ковалевская О.В., Серикова С.Н., Попандопуло К.И. Показатели заболеваемости и смертности от болезней органов пищеварения в Краснодарском крае и качество оказания медицинской помощи гастроэнтерологическим пациентам. Российский журнал гастроэнтерологии, гепатологии, колопроктологии. 2019;29(4):30-37. https://doi.org/10.22416/1382-4376-2019-29-4-30-37 


\title{
Indicators Of Morbidity And Mortality From Diseases of the Digestive System in the Krasnodar Krai and the Quality of Medical Care for Gastroenterological Patients
}

\author{
Natalia V. Korochanskaya ${ }^{1,2, *}$, Vladimir M. Durleshter ${ }^{1,2}$, Olga V. Kovalevskaya ${ }^{2}$, Svetlana N. Serikova $^{1,2}$, \\ Konstantin I. Popandopulo ${ }^{1}$ \\ ${ }^{1}$ Kuban State Medical University, Krasnodar Krai, Russian Federation \\ ${ }^{2}$ Regional Clinical Hospital No. 2, Krasnodar Krai, Russian Federation
}

\begin{abstract}
Aim. To analyse the dynamics of morbidity and mortality from diseases of the digestive system, as well as the quality of medical care for gastroenterological patients in the Krasnodar Krai.

Materials and methods. The analysis was carried out according to C 51 "Distribution of deaths by gender, age groups and causes of death" form of the Territorial Authority of the Federal State Statistics Service for the Krasnodar Krai for the period from 2006 to 2018, as well as on the basis of the "Demography" block database of the Parus software of the healthcare management system of the Krasnodar Krai for 6 months of 2019. 1341 medical records of patients receiving outpatient medical care and the medical records of people who had died from digestive diseases in 2017-2019 were reviewed.

Results. Digestive diseases (DD) occupy the fourth place (7.1\%) in the structure of the general morbidity of the population in the Krasnodar Krai. Over the study period (13 years), the structure of mortality from DD has not changed significantly among the region's population. About $70 \%$ of the causes of death from DD among people of working age account for liver diseases. The pathology of the pancreas takes the second place (13.5 \%). The peptic ulcer of the stomach, duodenum and "other diseases of the digestive system" ( $8.8 \%$ and $7.7 \%$, respectively) are represented in almost equal shares. In the etiological structure of liver cirrhosis, viral (39\%) and alcoholic (36 \%) liver diseases are leading. The frequency of viral liver lesions tends to decrease, while the proportion of liver cirrhosis in the outcome of non-alcoholic fatty liver disease (NAFLD) progressively increase, having reached 7\% in 2017-2018. In the group of patients with inflammatory diseases of the pancreas, men prevail (66.9\%), often those abusing alcohol. The third leading cause of mortality from DD in the Krasnodar Territory is pathological conditions that occurred in the upper gastrointestinal tract (acute stomach ulcer, duodenal ulcer with bleeding, perforation) in older age groups taking antiplatelet agents and non-steroidal anti-inflammatory drugs (71.8 \%).

Conclusions. The main causes of death among the population of the Krasnodar Krai from diseases of the digestive system at a young age are alcohol consumption with unhealthy consequences. At the same time, people of older age groups die from a lack of prevention of ulceration and inadequate eradication of Helicobacter pylori in patients taking non-steroidal anti-inflammatory drugs and antiplatelet agents.
\end{abstract}

Keywords: morbidity, mortality, digestive diseases

Conflict of interest: the authors declare no conflict of interest.

For citation: Korochanskaya N.V., Durleshter V.M., Kovalevskaya O.V., Serikova S.N., Popandopulo K.I. Indicators Of Morbidity And Mortality From Diseases of the Digestive System in the Krasnodar Krai and the Quality of Medical Care for Gastroenterological Patients. Russian Journal of Gastroenterology, Hepatology, Coloproctology. 2019;29(4):30-37. https://doi.org/10.22416/13824376-2019-29-4-30-37

Болезни органов пищеварения (БОП) входят в перечень предотвратимых причин смертности в трудоспособном возрасте [1], в связи с чем клиническая и социальная значимость гастроэнтерологических заболеваний весьма велика. Согласно данным Росстата [2] смертность от болезней органов пищеварения в Российской Федерации в последнее десятилетие стабильна и варьирует от 65,4 до 67,2 на 100000 населения. Стабильна и заболеваемость БОП в РФ - 4841 в 2010 году и 4986 в 2017 году. В структуре общей заболеваемости населения БОП удерживают стабильное 5-6-е место $(7,1-7,7 \%)$.

Для Краснодарского края актуальной задачей является снижение заболеваемости и смертности от БОП. Краснодарский край - крупнейший по численности населения регион России после Москвы и Московской области с населением на 1 января 2019 года 5648,2 тысяч человек, в том числе 3116,4 тысячи человек $(55,2 \%)$ - городские жители и 2531,8 тысячи человек $(44,8 \%)$ - жите- ли сельской местности. Прирост населения в крае в 2018 году, по сравнению с 2017, составил 44,9 тысячи человек [3]. Заболеваемость БОП в крае стабильна и в 2018 году составила 93,1 на 100000 населения (в 2014 году - 96,1 на 100000 населения). В структуре общей заболеваемости всего населения БОП занимают четвертое место ( $7,1 \%)$. В 2018 году, по сравнению с 2014 годом, показатели смертности от БОП в Краснодарском крае снизились на 22,3 \%. Удельный вес БОП в общей структуре смертности Краснодарского края составляет 4,8-5,3\%. В 2018 году на $17,1 \%$ снизилась смертность от БОП в Краснодарском крае и у лиц трудоспособного возраста (в 2014 году 46,1 на 100000 населения, в 2018 году $-38,2$ на 100000 населения).

В крае сформирована система контроля качества медицинской деятельности, объединяющая государственный, ведомственный и внутренний контроль, ведется мониторинг мероприятий по снижению смертности от БОП, осуществляются 
выезды в медицинские организации муниципальных образований Краснодарского края с целью оказания организационно-методической помощи.

Цель исследования: проанализировать динамику заболеваемости и смертности от болезней органов пищеварения, а также качество оказания медицинской помощи гастроэнтерологическим больным в Краснодарском крае.

Материал и методы. Анализ проводился по данным формы С 51 «Распределение умерших по полу, возрастным группам и причинам смерти» Территориального органа Федеральной службы государственной статистики по Краснодарскому краю за период с 2006 по 2018 год, а также на основании изучения базы данных блока «Демография» системы управления здравоохранением Краснодарского края программного продукта «Парус» в течение 6 месяцев 2018 года. Рецензированию подверглись 1341 медицинская карта пациентов, получающих медицинскую помощь в амбулаторных условиях, и истории болезни пациентов, умерших от БОП в 2017-2019 гг. Проанализированы результаты мониторинга качества оказания медицинской помощи пациентам с БОП, который ведется в Краснодарском крае в 2015-2019 гг.

Результаты исследования и обсуждение. Причины смерти от болезней органов пищеварения среди населения Краснодарского края с учетом прежде всего лиц трудоспособного возраста можно разделить условно на четыре основные (значимые) группы:

I группа - болезни печени, прежде всего циррозы печени и острый алкогольный гепатит;

II группа - доброкачественные воспалительные заболевания поджелудочной железы, в первую очередь, острый панкреатит;

III группа - осложнения язвенной болезни желудка, двенадцатиперстной кишки, гастропатии, ассоциированные с приемом нестероидных противовоспалительных препаратов (НПВП) и дезагрегантов;

IV группа - смерть как результат различных заболеваний желудочно-кишечного тракта, группа «Прочие болезни органов пищеварения». В эту группу входят заболевания пищевода, двенадцатиперстной кишки (кроме язвенной болезни желудка и двенадцатиперстной кишки), тонкой и толстой кишок, прямой кишки, в том числе гастроеюнальная язва с кровотечением, прободением, непроходимость двенадцатиперстной кишки, свищ желудка и двенадцатиперстной кишки, острые, хронические сосудистые болезни кишечника, дивертикулярная болезнь кишечника с различными осложнениями (прободением, кровотечением) и т. д.

За изучаемый период (13 лет) структура смертности населения Краснодарского края от БОП существенно не изменилась: на долю болезней печени приходится около 70 \% причин смерти от БОП лиц трудоспособного возраста, на втором месте заболевания поджелудочной железы (13,5 \%), и практически равные доли имеют язвенная болезнь желудка, двенадцатиперстной кишки и «прочие болезни органов пищеварения» $(8,8$ и 7,7 \% соответственно).

Патология печени как первоначальная причина смерти у мужчин трудоспособного возраста представлена алкогольным и токсическим поражением, фиброзом и циррозом печени с интенсивностью 28,4 случая на 100000 общего населения, максимальных значений коэффициент смертности на протяжении 13 лет достиг в 2010 году и составил 32,3\%. В возрастном аспекте пик смертности приходится на период от 40 до 60 лет.

По данным медицинских карт пациентов, получающих медицинскую помощь в амбулаторных условиях, и историй болезней нами была проанализирована этиологическая структура циррозов печени (ЦП) (см. рис. 1).

В этиологической структуре лидировали вирусные (39 \%) и алкогольные (36 \%) ЦП. Актуальность этой проблемы весьма велика. Во всем мире ЦП занимает 9-е место среди регистрируемых причин смерти, в России - 6-е место, опережая в структуре смертности такие грозные заболеваниях, как рак желудка, рак толстой кишки, инфекционные болезни [4]. Полученные нами данные совпадают с мнением ведущих гастроэнтерологов страны, согласно которому самым значимым этиологическим фактором ЦП остается хроническая алкогольная интоксикация [5-7]. По данным М.В. Маевской и соавт. (2016), причиной смерти от заболеваний органов пищеварения в 50-80\% случаев послужили циррозы печени, преимущественно алкогольной и вирусной этиологии [7].

В Краснодарском крае отмечена тенденция к снижению удельного веса циррозов печени в ис-

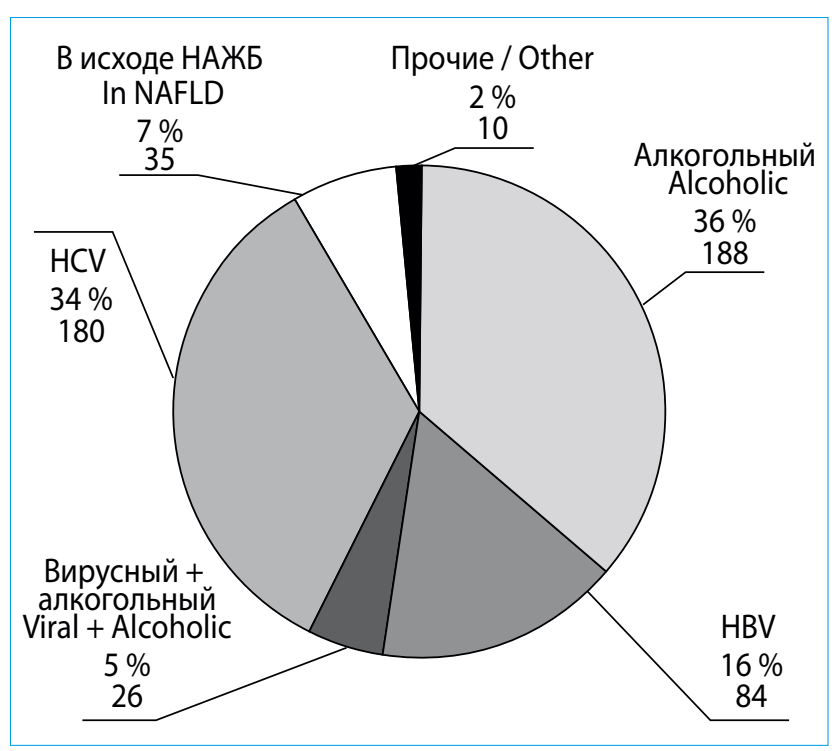

Рис. 1. Этиологическая структура циррозов печени в Краснодарском крае $(n=523)$

Fig.1. Etiological structure of liver cirrhosis in the Krasnodar Krai $(n=523)$ 
ходе хронических вирусных гепатитов, что связано с внедрением новых методов противовирусной терапии. В структуре хронических вирусных гепатитов на территории края на долю хронического гепатита С приходится 81,6 \% случаев; в 2018 году отмечено снижение заболеваемости на 2,42 \%. Показатель заболеваемости в 2018 году составил 29,81 на 100 тыс. населения (1646 случаев) против 30,55 на 100 тыс. населения (1676 случаев) в 2017 году [3].

Вместе с тем, согласно нашим данным, в этиологической структуре ЦП прогрессивно увеличивается удельный вес неалкогольной жировой болезни печени (НАЖБП), патогенетически тесно связанной с ожирением и другими проявлениями метаболического синдрома, который к 2017-2018 годам в Краснодарском крае достиг 7 \%. На схожие тенденции в РФ указывают В.Т. Ивашкин и соавторы [8, 9]. По данным этой группы исследователей, в Российской Федерации частота выявления НАЖБП в 2007 г. составила 27,0 \%, а в 2014 г. - 37,1 \% (прирост более $10 \%$ ), в результате чего она заняла первое место среди заболеваний печени - 71,6 \% [9].

С целью оценки адекватности оказания медицинской помощи этой группе больных нами были проанализированы 523 истории болезни и медицинские карты пациентов, умерших с диагнозом «цирроз печени». Проведенный анализ показал, что $176(33,7$ \%) пациентов с ЦП умерли на дому, $347(66,3 \%)$ - в стационаре. Обращала на себя внимание поздняя диагностика заболевания у 178 (34,0 \%) больных диагноз цирроза печени был поставлен в течение года, предшествовавшему летальному исходу. С целью своевременного выявления осложнений портальной гипертензии, в частности, кровотечений из варикозно расширенных вен пищевода (ВРВП), 201 пациент (38,4%) регулярно проходил эзофагогастродуоденоскопию, у 47 (8,9 \%) человек проводилось профилактическое лигирование ВРВП. Непосредственными причинами смерти пациентов в стационаре явились: продолжающееся (рецидивирующее) кровотечение из ВРВП - у 35 (6,7 \%) человек, рецидивирующее язвенное кровотечение - у 14 (2,7 \%) пациентов, прогрессирование полиорганной недостаточности - у 124 (23,7 \%), печеночной энцефалопатии - у $305(58,3 \%)$ человек, гепаторенальный синдром - у $43(8,2 \%)$ пациентов, тромбоэмболия легочной артерии - у 2 (0,4 \%) человек.

Вторыми по значимости в структуре смертности БОП являются воспалительные заболевания поджелудочной железы. У мужчин, страдающих патологией поджелудочной железы (сюда включен и алкогольный панкреатит), вероятность умереть в сравнении с больными I группы в 5 раз меньше, так как средняя интенсивность возникновения данной причины смерти составила за 13 лет 5,93\%. В этой группе превалируют мужчины - 66,9\%. Согласно мировой статистике, заболеваемость острым панкреатитом (ОП) во всем мире варьирует от 4,9 до 73,4 случаев на 100000 населения $[10,11]$. Исследователи отмечают, что при снижающихся показателях летальности удельный вес этого заболевания в структуре смертности остается стабильно высоким [11].

Третьей по значению причиной смертности от БОП в Краснодарском крае являются патоло-

Таблица 1. Заболеваемость вирусными гепатитами в Краснодарском крае за 2014-2018 гг. [3]

Table 1. Viral hepatitis morbidity in the Krasnodar Krai in 2014-2018 [3]

\begin{tabular}{|c|c|c|c|c|c|c|c|c|c|c|}
\hline \multirow[b]{2}{*}{$\begin{array}{c}\text { Заболевания } \\
\text { Disease }\end{array}$} & \multicolumn{2}{|c|}{2014} & \multicolumn{2}{|c|}{2015} & \multicolumn{2}{|c|}{2016} & \multicolumn{2}{|c|}{2017} & \multicolumn{2}{|c|}{2018} \\
\hline & $\begin{array}{c}\text { всего } \\
\text { чел. } \\
\text { total } \\
\text { pers. }\end{array}$ & $\begin{array}{c}\text { на } 100 \\
\text { тыс. нас. } \\
\text { per } 100 \\
\text { thousand } \\
\text { pop. }\end{array}$ & $\begin{array}{l}\text { всего } \\
\text { чел. } \\
\text { total } \\
\text { pers. }\end{array}$ & $\begin{array}{c}\text { на } 100 \\
\text { тыс. нас. } \\
\text { per } 100 \\
\text { thousand } \\
\text { pop. }\end{array}$ & $\begin{array}{l}\text { всего } \\
\text { чел. } \\
\text { total } \\
\text { pers. }\end{array}$ & $\begin{array}{c}\text { на } 100 \\
\text { тыс. нас. } \\
\text { per } 100 \\
\text { thousand } \\
\text { pop. }\end{array}$ & $\begin{array}{l}\text { всего } \\
\text { чел. } \\
\text { total } \\
\text { pers. }\end{array}$ & $\begin{array}{c}\text { на } 100 \\
\text { тыс. нас. } \\
\text { per } 100 \\
\text { thousand } \\
\text { pop. }\end{array}$ & $\begin{array}{l}\text { всего } \\
\text { чел. } \\
\text { total } \\
\text { pers. }\end{array}$ & $\begin{array}{c}\text { на } 100 \\
\text { тыс. нас } \\
\text { per } 100 \\
\text { thousand } \\
\text { pop. }\end{array}$ \\
\hline $\begin{array}{l}\text { Острый вирусный } \\
\text { гепатит, в т. ч. } \\
\text { Acute viral hepatitis, incl. }\end{array}$ & 232 & 4,41 & 143 & 2,69 & 167 & 3,07 & 307 & 5,60 & 177 & 3,21 \\
\hline A & 151 & 2,87 & 38 & 0,72 & 61 & 1,12 & 167 & 3,04 & 69 & 1,25 \\
\hline B & 36 & 0,68 & 35 & 0,66 & 29 & 0,53 & 47 & 0,86 & 22 & 0,40 \\
\hline $\mathrm{C}$ & 41 & 0,78 & 68 & 1,28 & 76 & 1,40 & 91 & 1,66 & 83 & 1,5 \\
\hline E & 1 & 0,02 & - & - & - & - & - & - & - & - \\
\hline $\begin{array}{l}\text { Хронический вирусный } \\
\text { гепатит, в т. ч. } \\
\text { Chronic viral hepatitis, incl. }\end{array}$ & 1948 & 37,1 & 1949 & 36,69 & 1640 & 30,16 & 2000 & 36,46 & 2019 & 36,56 \\
\hline $\mathrm{B}$ & 348 & 6,61 & 361 & 6,8 & 301 & 5,54 & 323 & 5,89 & 371 & 6,72 \\
\hline $\mathrm{C}$ & 1597 & 30,35 & 1584 & 29,82 & 1339 & 24,62 & 1676 & 30,55 & 1646 & 29,81 \\
\hline $\begin{array}{l}\text { Носители HBsAg } \\
\text { HBsAg carriers }\end{array}$ & 329 & 6,25 & 277 & 5,21 & 198 & 3,64 & 168 & 3,06 & 150 & 2,72 \\
\hline
\end{tabular}




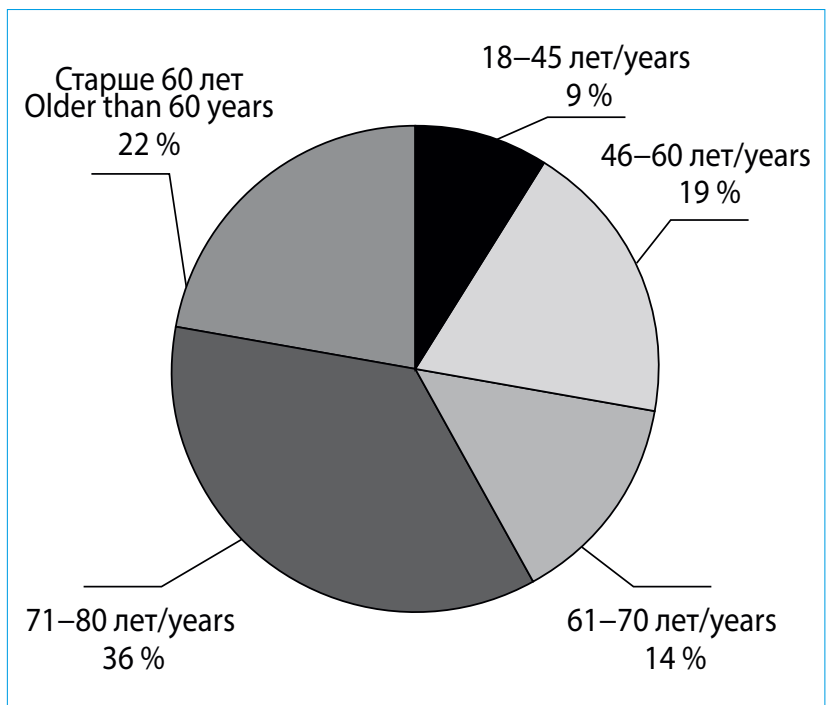

Рис. 2. Возрастной состав лиц, умерших с диагнозом «язва желудка и двенадцатиперстной кишки» (К25К28) в 2017-2018 гг. (818 чел.)

Fig. 2. The age of patients having died of stomach and duodenum ulcer (K25-K28) in 2017-2018 (818 persons)

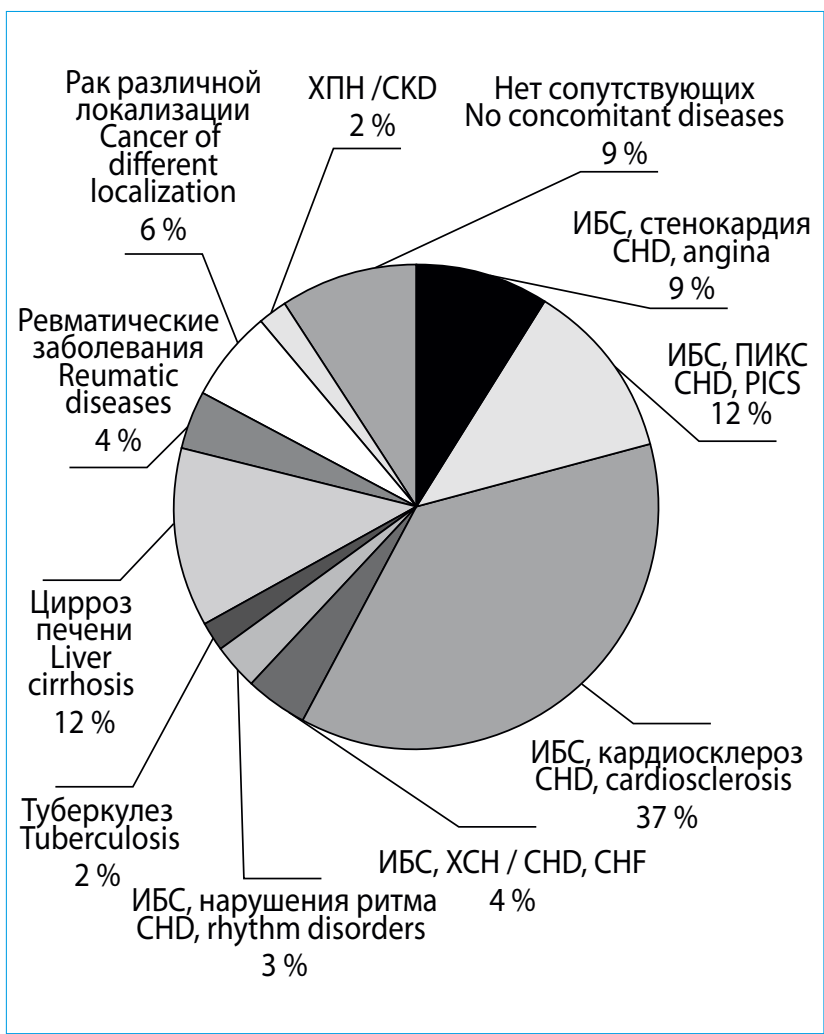

Рис. 3. Структура сопутствующих заболеваний у больных, умерших с диагнозом «язва желудка и двенадцатиперстной кишки» в 2017-18 гг. (К25-К28)

Fig. 3. The structure of concomitant diseases in patients having died of stomach and duodenum ulcer (K25-K28) in 2017-2018

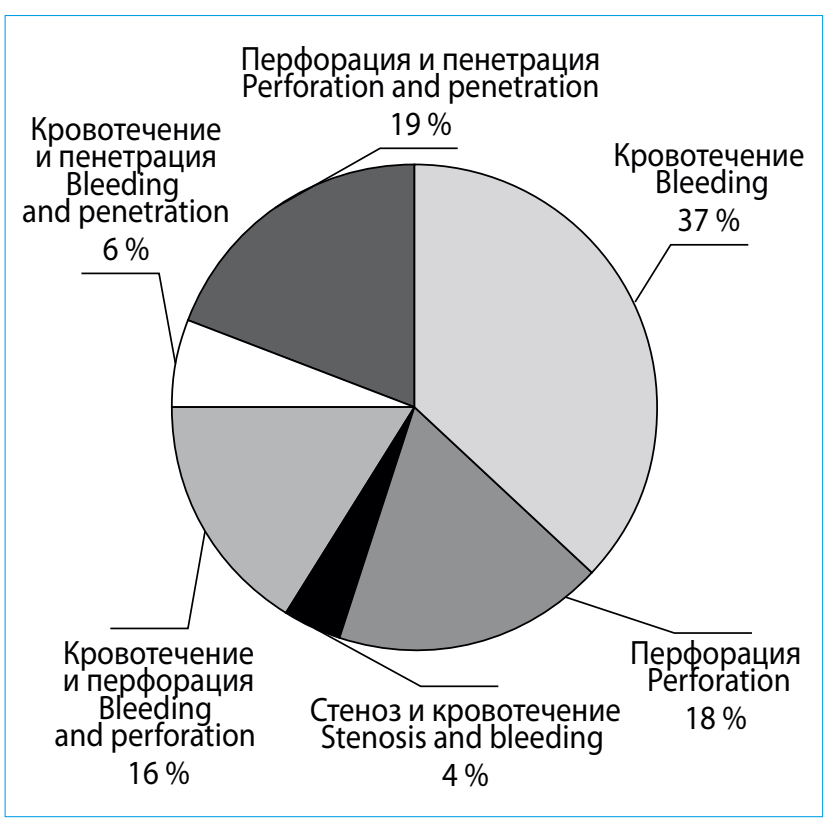

Рис. 4. Структура осложнений у лиц, умерших с диагнозом «язва желудка и двенадцатиперстной кишки» в 2017-18 гг. (К25-К28)

Fig. 4. The structure of complications in patients having died of stomach and duodenum ulcer (K25-K28) in $2017-2018$

гические состояния, возникшие в верхних отделах желудочно-кишечного тракта (острая язва желудка, двенадцатиперстной кишки с кровотечением, прободением), требующие неотложной медицинской помощи.

Нами были проанализированы медицинские карты пациентов, получающих медицинскую помощь в амбулаторных условиях, и истории болезни больных, умерших в Краснодарском крае с диагнозом «язва желудка и двенадцатиперстной кишки» (К25-К28) в 2017-2018 годах $(n=818)$ (рис. 2, 3).

При анализе медицинской документации обращало на себя внимание, что 589 (72 \%) человек были старше трудоспособного возраста, причем из них 180 (22 \%) человек были старше 80 лет (рис. 2). Согласно рис. 3, только 9 \% умерших не имели сопутствующих заболеваний, у остальных в качестве конкурирующих заболеваний преобладали различные формы ишемической болезни сердца (65 \%), у лиц молодого возраста - ревматические заболевания (4\%) и цирроз печени (12 \%). Превалировали острые осложнения язвенных поражений желудка и двенадцатиперстной кишки: кровотечения (37 \%), перфорации (19\%), сочетания кровотечения и перфорации (16 \%) (рис. 4). Согласно медицинской документации, прием нестероидных противовоспалительных препаратов (НПВП) и дезагрегантов отмечен в анамнезе у 587 (71,8 \%) умерших.

Анализ медицинских карт пациентов, получающих медицинскую помощь в амбулаторных условиях, и историй болезни умерших продемонстри- 
ровал, что в ряде случаев при назначении НПВП и дезагрегантов не учитывались факторы риска повреждения слизистой оболочки желудка и двенадцатиперстной кишки, своевременно не проводилось тестирование на Helicobacter pylori, эрадикационная и антисекреторная терапия.

Анализ диагнозов пациентов, умерших в результате различных заболеваний пищевода, кишечника (IV группа), свидетельствовал о том, что в трудоспособном возрасте их было немного - 8,3 \% случаев, при этом мужчины составляли 65 \%, женщины - 35 \%. Вместе с том, проведенное исследование свидетельствует, что после 60 лет формируется устойчивая тенденция к интенсивному росту случаев смерти в этой группе. Причина кроется в увеличении частоты острой сосудистой патологии кишечника. Доля сосудистой патологии кишечника, включающая в основном острую сосудистую патологию, у лиц трудоспособного возраста составляет 3,7 \%, после 60 лет увеличивается до 63,6 \%. Это совпадает с данными литературы, согласно которым [12] острая мезентериальная ишемия является следствием атеросклероза, ревматических пороков сердца, гипертонической болезни и нарушений сердечного ритма.

Анализ структуры смертности у женщин трудоспособного возраста позволяет говорить о том, что они при аналогичных клинических ситуациях умирают в 4 раза реже, чем мужчины, средняя интенсивность той или иной причины смерти от патологии органов пищеварения у мужчин составила $42,16 \pm 2,2$ \% , у женщин - 11,48 \pm 0,71\%о.

\section{Выводы}

1. Болезни органов пищеварения являются клинически и социально значимыми заболеваниями. Основными причинами смерти населения Краснодарского края от болезней органов пищеварения в молодом возрасте являются употребление алкоголя с вредными для здоровья последствиями, у лиц старших возрастных групп - отсутствие профилактики язвообразования и неадекватная эрадикация Helicobacter pylori у лиц, принимающих нестероидные противовоспалительные препараты и дезагреганты, ишемический колит.

2. В Краснодарском крае женщины от причин, связанных с патологий органов пищеварения, умирают в 4 раза реже, чем мужчины. Основная масса случаев смерти приходится на пенсионный возраст за исключением патологии печени, когда фиброз, цирроз печени приводят к смерти в трудоспособном возрасте как среди женщин, так и среди мужчин.

3. Для совершенствования качества оказания медицинской помощи этой группе больных необ- ходимо регулярно проводить анализ сложившейся демографической ситуации, анализировать допущенные ошибки и на основе проведенного анализа вырабатывать организационные решения, направленные на оптимизацию оказания медицинской помощи. На необходимость проведения такого анализа неоднократно указывал главный внештатный гастроэнтеролог министерства здравоохранения РФ академик В.Т. Ивашкин. Представленный анализ демографической ситуации в регионах (в том числе и в Краснодарском крае) обсуждался на объединенных заседаниях профильной комиссии Минздрава и главных гастроэнтерологов субъектов РФ в рамках XXIII и XXIV Российских гастроэнтерологических недель (2017, 2018 гг., Москва, Россия).

4. В крае разработан и внедряется комплекс мероприятий, направленных на оптимизацию качества оказания медицинской помощи пациентам с гастроэнтерологической патологией. Экспертиза историй болезни и медицинских карт пациентов, получающих медицинскую помощь в амбулаторных условиях, умерших от БОП, проведена в $100 \%$ случаев. При выявлении грубых ошибок при оказании медицинской помощи этой группе пациентов проводятся выездные лечебно-контрольные комиссии в медицинских организациях муниципальных образований края с разбором ошибок в тактике ведения пациентов с социально и клинически значимыми БОП.

5. Краевыми клиническими больницами осуществляется ежедневный мониторинг в курируемых медицинских организациях тяжело больных с БОП с активным выходом на телемедицинские консультации. Количество телеконсультаций больных с БОП увеличилось со 112 (в 2017 году) до 421 (2018 год).

6. Внедрены в работу медицинских организаций муниципальных образований методические рекомендации по лечению пациентов с социально и клинически значимыми заболеваниями (язвенная болезнь, циррозы печени, ишемический колит) с постоянным контролем их наличия на рабочих местах их применением. Регулярно проводятся научно-практические конференции по вопросам оказания медицинской помощи пациентам с БОП совместно с врачами других специальностей (хирурги, эндоскописты, наркологи, неврологи, кардиологи), учитывая полиморбидность пациентов. Осуществляется проведение вебинаров, включающих практические рекомендации по тактике ведения пациентов с клинически и социально значимыми заболеваниями (в 2017 году - 6 вебинаров, в 2018 году - 11 вебинаров, в 1-м полугодии 2019 года - 4). 


\section{Литература / References}

1. Nolte E., McKee M. Measuring the health of the nations: analysis of mortality amenable to health care. BMJ.2003;327:1129. DOI: 10.1136/bmj.327.7424.1129

2. Здравоохранение в России. 2015. Статистический сборник. М: Росстат, 2015. С. 174. [Healthcare in Russia. 2015. Stat. Issue / Russtat. M., 2015. 174 p. (In Russ.)].

3. Администрация Краснодарского края, Министерство здравоохранения Краснодарского края; под общ. ред. Е.Ф. Филиппова. О состоянии здоровья населения и организации здравоохранения Краснодарского края по итогам 2018 года: государственный доклад. Краснодар: ГБУЗМИАЦ, 2019. С. 162. [Population health and health care organization in Krasnodar Regionin 2018 year: state report / Administration of Krasnodar Region, Ministry of health care of Krasnodar Region; edited by E.F. Filippov. Krasnodar: SBIHCMIAC. 162 p. (In Russ.)].

4. http://www.euro.who.int/en/data-and-evidence/archive/ mortality-database-updated

5. Хазанов А.И. Из полувекового опыта наблюдения за больными циррозом печени. Рос журн гастроэнтерол гепатол колопроктол. 1998;8(2):50-60. [Khazanov A.I. 50-years monitoring of patients with hepatic cirrhosis. Rus J Gastroenterol Hepatol Coloproctol. 1998;8(2):50-60 (In Russ.)].

6. Плюснин С.В., Ивашкин К.В., Бобров А.Н., Белякин С.А., Плюснина И.В. Алкогольная болезнь печени: первичная и вторичная профилактика. Рос журн гастроэнтерол гепатол колопроктол. 2015;25(3):42-8. [Plyusnin S.V., Ivashkin K.V., Bobrov A.N., Belyakin S.A., Plyusnina I. V. Alcohol-induced liver disease: primary and secondary prevention. Rus J Gastroenterol Hepatol Coloproctol. 2015;25(3):42-8 (In Russ.)].

7. Маевская М.В., Бакулин И.Г., Чирков А.А., Люсина Е.О., Луньков В.Д. Злоупотребление алкоголем среди пациентов гастроэнтерологического профиля. Рос журн гастроэнтерол гепатол колопроктол. 2016;26(4):24-35. [Mayevskaya M.V., Bakulin I.G., Chirkov A.A., Lyusina Y.O., Lun'kov V.D. Alcohol abuse in gastroentero- logical patients. Rus J Gastroenterol Hepatol Coloproctol. 2016;26(4):24-35 (In Russ.)]. DOI: 10.22416/1382-43762016-26-4-24-35

8. Ивашкин В.Т., Драпкина О.М., Шульпекова Ю.О. Диагностика и лечение неалкогольной жировой болезни печени: Методические рекомендации. М.: M-Вести, 2009. С. 20. [Ivashkin V.T., Drapkina O.M., Shul'pekova Yu.O. Diagnostics and treatment of nonalcoholic steatosis liver disease: Method. recomendation. Moscow: M-Vesti, 2009. 20 p. (In Russ.)].

9. Ивашкин В.Т., Маевская М.В., Павлов Ч.С., Тихонов И.Н., Широкова Е.Н., Буеверов А.О., Драпкина О.М., Шульпекова Ю.О., Цуканов В.В., Маммаев С.Н., Маев И.В., Пальгова Л.К. Клинические рекомендации по диагностике и лечению неалкогольной жировой болезни печени Российского общества по изучению печени и Российской гастроэнтерологической ассоциации. Рос журн гастроэнтерол гепатол колопроктол. 2016;26(2):24-42. [Ivashkin V.T., Mayevskaya M.V., Pavlov C.S., Tikhonov I.N., Shirokova Y.N., Buyeverov A.O., Drapkina O.M., Shulpekova Y.O., Tsukanov V.V., Mammayev S.N., Mayev I.V., Palgova L.K. Diagnostics and treatment of non-alcoholic fatty liver disease: clinical guidelines of the Russian Scientific Liver Society and the Russian gastroenterological association. Rus J Gastroenterol Hepatol Coloproctol. 2016;26(2):24-42 (In Russ.)]. DOI: 10.22416/1382-4376-2016-26-2-24-42

10. Fagenholz P.J., Castillo C.F., Harris N.S. et al. Increasing United States hospital admissions for acute pancreatitis, 1988-2003. Ann Epidemiol. 2007;17:491-7.

11. Yadav D., Lowenfels A.B. Trends in the epidemiology of the first attack of acute pancreatitis: a systemic review. Pancreas 2006;33:323-30.

12. Brandt L., Fuerstadt P., Longstreth P., Boley S. ACG Clinical Guideline: epidemiology, risk factors, patterns of presentation, diagnosis, and management of colon ischemia. Am J Gastroenterol. 2015;110:18-44.

\section{Сведения об авторах}

Корочанская Наталья Всеволодовна* - доктор медицинских наук, профессор, профессор кафедры хирургии № 3 ФГБОУ ВО «Кубанский государственный медицинский университет» Министерства здравоохранения Российской Федерации, руководитель гастроэнтерологического центра ГБУЗ «Краевая клиническая больница № 2» Министерства здравоохранения Краснодарского края.

Контактная информация: nvk-gastro@mail.ru;

350063, г. Краснодар, ул. им. Митрофана Седина, д. 4.

Дурлештер Владимир Моисеевич - доктор медицинских наук, профессор, заведующий кафедрой хирургии № 3 ФГБОУ ВО «Кубанский государственный медицинский университет» Министерства здравоохранения Российской Федерации, заместитель главного врача по хирургии ГБУЗ «Краевая клиническая больница № 2» Министерства здравоохранения Краснодарского края.

Контактная информация: durleshter59@mail.ru;

350063, г. Краснодар, ул. им. Митрофана Седина, д. 4.

Ковалевская Ольга Витальевна - кандидат медицинских наук, заместитель главного врача по клинико-экспертной и организационно-методической работе ГБУЗ «Краевая клиническая больница № 2» Министерства здравоохранения Краснодарского края.

Контактная информация: kovalevskaya.bms@mail.ru;

350012, г. Краснодар, ул. Красных Партизан, д. 6/2.

\section{Information about the authors}

Natalia V. Korochanskaya* - Dr. Sci. (Med.), Prof., Surgical Department No. 3, Kuban State Medical University; Head, Gastroenterological Centre, Regional Clinical Hospital No. 2. Contact information: nvk-gastro@mail.ru; 350063, Krasnodar, Mitrofana Sedina str., 4.

Vladimir M. Durleshter - Dr. Sci. (Med.), Prof., Departmental Head, Surgical Department No.3, Kuban State Medical University; Deputy Chief Physician on Surgery, Regional Clinical Hospital No. 2.

Contact information: durleshter59@mail.ru;

350063, Krasnodar, Mitrofana Sedina str., 4.

Olga V. Kovalevskaya - Cand. Sci. (Med.), Deputy Chief Physician on Clinical-Expert and Organizational-Methodological Work, Regional Clinical Hospital No. 2.

Contact information: kovalevskaya.bms@mail.ru;

350012, Krasnodar, Krasnykh Partizan str., 6/2. 
Серикова Светлана Николаевна - доктор медицинских наук, доцент кафедры хирургии № 3 ФГБОУ ВО «Кубанский государственный медицинский университет» Министерства здравоохранения Российской Федерации, руководитель гастроэнтерологического центра ГБУЗ «Краевая клиническая больница № 2» Министерства здравоохранения Краснодарского края.

Контактная информация: serikovasn@mail.ru;

350063, г. Краснодар, ул. им. Митрофана Седина, д. 4.

Попандопуло Константин Иванович - доктор медицинских наук, заведующий кафедрой факультетской хирургии с курсом анестезиологии и реаниматологии «Кубанский государственный медицинский университет» Министерства здравоохранения Российской Федерации.

Контактная информация: kip.kip59@mail.ru;

350063, г. Краснодар, ул. им. Митрофана Седина, д. 4.
Svetlana N. Serikova - Dr. Sci. (Med.), Assoc. Prof., Surgical Department No.3, Kuban State Medical University; Head, Gastroenterological Centre, Regional Clinical Hospital No. 2. Contact information: serikovasn@mail.ru;

350063, Krasnodar, Mitrofana Sedina str., 4.

Konstantin I. Popandopulo - Dr. Sci. (Med.), Departmental Head, Department of Faculty Surgery with an Anesthesiology and Reanimatology Course, Kuban State Medical University. Contact information: kip.kip59@mail.ru;

350063, Krasnodar, Mitrofana Sedina str., 4.

Поступила: 09.07.2019 Принята после доработки: 25.07.2019 Опубликована: 30.08.2019 Submitted: 09.07.2019 Revised: 25.07.2019 Published: 30.08.2019

* Автор, ответственный за переписку / Corresponding author 